\title{
PEMBELAJARAN TAHSIN TILAWAH AL-QUR'AN UNTUK PEMBACA PEMULA
}

\author{
Baktiar Leu \\ Prodi Pendidikan Agama Islam Sekolah Tinggi Agama Islam (STAI) Kupang \\ e-mail: baktiar.leu@gmail.com
}

\begin{abstract}
It cannot be denied that the verses of the Quran are arranged with Arabic vocabulary. Except for a few words that entered the treasury duw tho acculturation. The Quran recognizes this in its many verses, including those that refute the accusation that the Quran was recommended by 'Ajam (nonArab) to the Prophet Allah. Arabic grammar is also very rational and Indonesian but it is quite complicated, especially when compared to. AlQur'an as a guide life for every Muslim. As a guide, of course we must always read it and understand its contents. In order to read properly and correctly according to the rules of recitation, it is necessary for us to study the Qur'an, especially learning how to read it. Through this Qur'an recitations we are trying to improve and smooth the reading of the Qur'an. Because reading and reciting letters of the Qur'an properly and correctly they are Muslims. Therefore, the writer of study about how Learning to Resist the Recitations of the Quran, for beginners Readers (Learning of the Quran, Good and Islamic way of being able to read the Quran well and in accordance with the rules that want to express is what the people believe). The approach uses a qualitative approach with data collection techniques in the form of document studies. While the data analysis technique uses content analysis is analyzes the contents of reading material related to this research. The results of the study explained that the recitation of the recitations of the Qur'an is an activity that emphasizes more on the correction or improvement of the reading of the Qur'an including makhorijul letters, letter character, relationship between letters, mad (long and short in reciting verses) and waqaf (start reading and stop at reading) as well as terms in the Qur'an
\end{abstract}

Keywords: Tahsin, Tilawah, Al-Qur'ān

\section{PENDAHULUAN}

Sebagai upaya untuk meningkatkan sumber daya manusia berkualitas, agar menjadi khairu ummah, diperlukan ilmu. Dengan ilmu/hikmah, maka kita dapat melihat dan membaca dalam keadaan gelap sekalipun. Ilmu adalah teman kita ketika dalam kesepian. Ilmu akan membawa kita dari cahaya gelap kepada cahaya yang terang benderang. 
Menuntut, mencari, menggali dan mengamalkan ilmu itu memerlukan kemampuan membaca (reading), menulis (writing), dan menghitung (aritmatic). Karena sesungguhnya Iqra' (perintah membaca) adalah merupakan perintah Allah SWT yang dituangkan dalam al-Qur'ān surat al-Alaq dengan maksud mencerdaskan manusia ${ }^{1}$.

Islam melalui sistem pendidikan dapat mengarahkan dan mencerdaskan kehidupan seseorang, berlandaskankan sumber etika dan nilai yang paling shahih yaitu al-Qur'ān dan sunnah Nabi Muhammad SAW. Al-Qur'ān secara bahasa berarti “bacaan sempurna". Menjadi suatu nama pilihan Allah yang sungguh tepat karena tiada satu bacaanpun yang dapat menandinginya. Dihafal oleh setiap orang baik muda maupun tua, anak-anak, remaja maupun dewasa, laki-laki maupun perempuan ${ }^{2}$.

Sungguh agung firman Allah ini, dijadikan pedoman hidup oleh seluruh kaum Muslimin. Membacanya bernilai ibadah dan mengamalkannya merupakan kewajiban yang diperintahkan oleh agama ${ }^{3}$.

Begitu detail aturan atau tata cara membacanya, mana yang dipendekkan, dipanjangkan, dipertebal atau diperhalus ucapannya, tempat yang terlarang atau boleh, atau harus memulai dan berhenti, bahkan diatur lagu dan iramanya sampai kepada etika membacanya ${ }^{4}$.

Nabi Muhammad SAW selalu menghimbau umatnya agar banyak membaca al-Qur'ān, baik bagi orang yang memahaminya ataupun yang tidak memahaminya. Semua akan mendapat pahala dari Allah SWT. Masing-masing huruf yang dibaca mendapat satu kebaikan sampai sepuluh kebaikan bahkan lebih sesuai dengan kualitas bacaan dan keikhlasannya dalam membaca ${ }^{5}$. Sebagaimana sabdanya:

${ }^{1}$ K.H. Ahmad Rifa'i Yasin, Panduan Tajwid Praktis, (Jakarta: Afwaaja-Nizhom, 2000), 6

${ }^{2}$ M. Quraish Shihab, Wawasan Al-Qur'a $>n$ Tafsir Maudhu'i Atas Pelbagai Persoalan Umat (Bandung: Mizan, 2007 ), 3.

${ }^{3}$ Lynda Fitri Ariyanti, Skripsi:Implementasi Metode Tabsin Dalam Pembelajaran Membaca Al-Qur'andi Smp Negeri 4 Ungaran Kabupaten Semarang Tabun Ajaran 2016/2017, (Salatiga, 2016)

${ }^{4}$ Op.cit., h. 4.

${ }^{5}$ Ahmad Annuri, Panduan Tahsin Tilawah Al-Qur'a>n \& Ilmu Tajwid (Jakarta: Pustaka Al-Kautsar, 2015), xxviii 


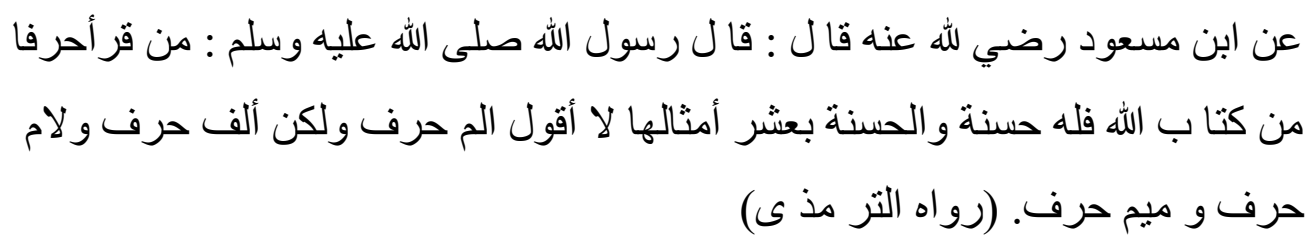

"Dari Ibnu Mas'ud ra, bahwasannya Rasulullah SAW Berkata: "Barang siapa yang membaca satu huruf dari Al-Qur'an, maka baginya satu kabaikan. Dan satu kebaikan itu dilipatgandakan menjadi sepuluh kali lipat. Saya tidak mengatakan bahwa alif lam mim satu huruf, akan tetapi alif itu satu huruf, lam itu satu huruf, dam mim itu satu huruf'"(HR. Tirmidzi)

Al-Qur'ān wajib dibaca dengan baik dan benar. Salah dalam melafalkan huruf saat membaca bisa mengubah makna ${ }^{7}$. Oleh karenanya, belajar membaca dan melafalkan huruf al-Qur'ān dengan baik dan benar menjadi kewajiban yang mengikat bagi setiap orang Islam. Bacaan yang baik dan benar itu harus sesuai dengan kaidah ilmu tajwid.

Dalam ilmu qira'ah, tajwid berarti membunyikan atau mengucapkan huruf dari tempatnya dengan memberikan sifat-sifat yang dimilikinya. Dengan demikian maka ilmu tajwid merupakan suatu ilmu yang menerangkan bagaimana cara melafazdkan atau mengucapkan huruf-huruf yang terdapat dalam kitab suci alQur'ān ${ }^{8}$.

Sebagai warga masyarakat yang beragama Islam, kemampuan membaca alQur'ān merupakan keterampilan yang sangat mendasar dan urgen. Namun dari data penelitian yang dilakukan oleh lembaga-lembaga penelitian, terungkap fakta bahwa masih banyak pelajar sekolah tingkat dasar, menengah pertama, menengah atas bahkan mahasiswa perguruan tinggi yang belum baik dan lancar membaca alQur'ān ${ }^{9}$.

IIbid., 21.

${ }^{7}$ Ibid, xxxiii.

${ }^{8}$ Muhammad Ishak Syafaruddin Masganti Sit, Pelaksanaan Program Tilawah Al-Qur'an dalam Meningkatkan Kemampuan Membaca Al-Qur'an Siswa di Mas AlMa'sum Stabat", (Pascasarjana UIN Sumatera Utara, 2017), 614

${ }^{9}$ Ahmad Hasim Fauzan, Pola Pembinaan Baca Tulis Al-Qur'an (BTQ) Sebagai Upaya Peningkatan Kemampuan Membaca Al-Qur'an, www.google.com 
Pada mahasiswa Sekolah Tinggi Agama Islam Kupang misalnya, penulis temukan fakta bahwa masih banyak mahasiswa yang belum bisa membaca al-Qur'ān dengan baik dan benar sesuai dengan kaidah ilmu tajwid. Hal ini disebabkan bukan hanya karena latar belakang mahasiswa Sekolah Tinggi Agama Islam Kupang lulusan dari Madrasah Aliyah dan sekolah-sekolah umum seperti sekolah menengah atas, sekolah menengah kejuruan, tetapi juga karena kesadaran umat untuk mempelajari cara/metode membaca al-Qur'ān secara baik dan benar masih sangat rendah, sehingga sulit untuk memberikan bimbingan kepada anak-anaknya dalam mempelajari al-Qur'ān sejak dini.

Dengan adanya permasalahan inilah, maka penulis merasa perlu untuk membahas lebih dalam tentang "Pembelajaran Tahsin Tilawah al-Qur'ān Bagi Pembaca Pemula dengan tujuan agar mahasiswa mampu membaca al-Qur'ān secara baik dan benar sesuai dengan kaidah ilmu tajwid. Yakinlah bahwa belajar al-Qur'ān, bahasanya, mempelajari bacaannya, menghafalkannya, memahami isinya dan mengamalkannya serta mengajarkannya itu mudah, sesuai dengan janji Allah SWT dalam QS. al-Qamar ayat: 17:

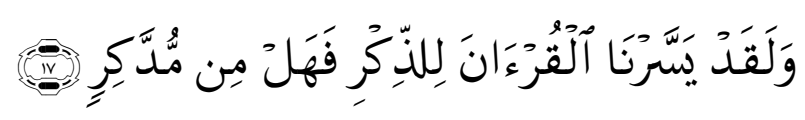

Dan Sesungguhnya telah Kami mudahkan Al-Quran untuk pelajaran, Maka Adakah orang yang mengambil pelajaran ${ }^{10}$.

Kemudahan itu bukanlah sesuatu yang bisa diraih dengan bersantai-santai, tetapi harus dilakukan dengan niat yang lurus dan usaha yang sangat maksimal. Sejarah perkembangan keislaman menyebutkan bahwa pembelajaran al-Qur'ān merupakan tradisi tertua. Dimasa Rasulullah, para murid/sahabat itu berupaya memenuhi keinginannya untuk belajar dan memahami ayat-ayat al-Qur'ān dilakukan secara bertahap hingga mereka benar-benar memahaminya secara utuh ${ }^{11}$.

${ }^{10}$ Al-Jumanatul 'Ali, Al-Qur'an dan terjemahnya, (Bandung: CV Penerbit J-ART, 2003), 530.

11 Tamrin, Pola Pembinaan Tabsin Dikalangan Mahasiswa, www. Google.com 


\section{PEMBAHASAN}

\section{A. PengertianTahsin Tilawah Al-Qur'ān}

1. Tahsin menurut bahasa berarti memperbaiki, membaguskan, menghiasi, mempercantik dan membuat lebih baik dari semula ${ }^{12}$. Ini berarti bahwa ada tuntutan agar dalam membaca al-Qur'ān harus benar dan tepat sesuai dengan contohnya demi terjaganya keaslian praktik tilawah sesuai dengan sunnah Rasulullah SAW ${ }^{13}$.

2. Tilawah menurut bahasa artinya bacaan. Sedangkan secara istilah ialah membaca al-Qur'ān dengan bacaan yang menjelaskan huruf-hurufnya dan berhati-hati dalam melaksanakan bacaannya, serta melafalkan dengan nada yang indah ${ }^{14}$.

Allah SWT berfirman (Q.S al-Muzzammil ayat 4):

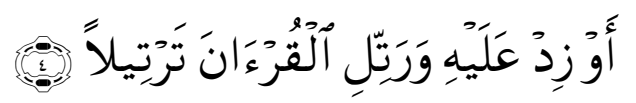

Atau lebih dari seperdua itu. dan bacalah al-Qur'ān itu dengan perlahan-lahan. ${ }^{15}$

Membaca dengan tartil artinya membaca dengan teratur (tidak terburu-buru) dan benar, sesuai dengan aturan-aturan ilmu tajwid, serta mengetahui tempat-tempat waqafnya ${ }^{16}$. Tajwid menurut bahasa berarti membaguskan, menyempurnakan, memantapkan. Sedangkan menurut istilah adalah ilmu yang berguna untuk mengetahui bagaimana cara memberikan hak huruf dan mustahaqnya. Maksud dari haq huruf itu adalah sifat asli yang melekat, seperti keluar nafas, tidak keluar nafas, suara tertekan, suara terlepas dan lain sabagainya. Sedangkan yang dimaksud dengan mustahaq huruf adalah sifat yang tampak sewaktu-

\footnotetext{
${ }^{12}$ Ahmad Annuri, Panduan Tahsin Tilawah Al-Qur'an \& Ilmu Tajwid (Jakarta: Pustaka Al-Kautsar, 2015), 3.

${ }^{13}$ Wikipedia Bahasa Indonesia, Tahsin, id.m.wikipedia.org/wiki/tahsin ${ }^{14}$ Op.Cit, 3.

15 Al-Jumanatul 'Ali, Al-Qur'an dan terjemahnya, (Bandung: CV Penerbit J-ART, 2003), 575.

16 K.H. Ahmad Rifa’i Yasin, Panduan Tajwid Praktis, (Jakarta: Afwaaja-Nizhom, 2000), 8
} 
waktu seperti tebal, tipis, samar dan lain sebagainya, termasuk yang berkaitan dengan $\operatorname{mad}^{17}$.

Ilmu tajwid tidak sekedar teori tetapi juga praktik. Banyak sekali orang menguasai teori tajwid, tetapi jika tidak membaca secara langsung dengan guru, sesungguhnya itu tak banyak berarti. Seperti ilmu bela diri dan bahasa (Arab atau Inggris), jika hanya belajar dari buku tanpa adanya praktik dan belajar langsung dari orang yang menguasainya, niscaya hasilnya tidak akan maksimal ${ }^{18}$.

Adapun hukum mempelajari tahsin tilawah adalah fardu kifayah. Sedangkan hukum membaca al-Qur'ān secara tajwid adalah fardu ain. Ini berarti bahwa membaca al-Qur'ān dengan menggunakan tajwid menjadi wajib bagi setiap orang. Bagi yang membaca al-Qur'ān tidak mempergunakan tajwid maka hukumnya dosa.

Ada beberapa istilah berkaitan dengan tajwid, diantaranya:

a) Tempat keluarnya huruf.

b) Sifat huruf, yaitu cara melafalkan atau mengucapkan huruf.

c) Hubungan antara huruf.

d) Hukum mad yaitu panjang dan pendeknya dalam melafazkan ayat alQur'ān

e) Waqaf yaitu tempat mulai dan berhenti pada bacaan ${ }^{19}$.

3. Al-Qur'ān

Secara bahasa al-Qur'ān berarti "bacaan" atau "sesuatu yang dibaca berulang-ulang”. Adapun secara istilah adalah kitab suci umat Islam yang di dalamnya berisi firman Allah SWT yang diturunkan kepada Rasulullah SAW sebagai mukjizat.

Berikut ini adalah beberapa pengertian al-Qur'ān menurut para ahli:

${ }^{17}$ Ahmad Annuri, Panduan Tahsin Tilawah Al-Qur'an \& Ilmu Tajwid (Jakarta: Pustaka Al-Kautsar, 2015), 17.

${ }^{18}$ Lynda Fitri Ariyanti, Skripsi:Implementasi Metode Tabsin Dalam Pembelajaran Membaca Al-Qur'andi Smp Negeri 4 Ungaran Kabupaten Semarang Tabun Ajaran 2016/2017, (Salatiga, 2016)

${ }^{19}$ Muhammad Ishak Syafaruddin Masganti Sit, Pelaksanaan Program Tilawah Al-Qur'an dalam Meningkatkan Kemampuan Membaca Al-Qur'an Siswa di Mas AlMa'sum Stabat", (Pascasarjana UIN Sumatera Utara, 2017), 606. 
a. Subhi As-Salih

Menurut Subhi As-Salih, al-Qur'ān adalah kalam Allah SWT sebagai sebuah mukjizat yang diturunkan kepada Nabi Muhammad SAW, ditulis dalam mushaf dan diriwayatkan secara mutawatir dan membacanya adalah termasuk ibadah.

b. Muhammad Ali Ash-Shabuni

Menurut Muhammad Ali ash-Shabuni, al-Qur'ān adalah firman Allah SWT yang tidak ada tandingannya, diturunkan kepada Nabi Muhammad SAW penutup para nabi dan rasul dengan perantara malaikat Jibril as, ditulis kepada mushaf-mushaf yang kemudian disampaikan kepada kita dengan cara mutawatir. Membaca dan mempelajari al-Qur'ān adalah ibadah dan dimulai dari surat al-Fatihah serta diakhiri dengan surat al-Nas.

c. Syekh Muhammad Khudari Beik

Menurut Syekh Muhammad Khudari Beik, al-Qur'ān merupakan firman Allah SWT yang berbahasa Arab, diturunkan kepada Nabi Muhammad SAW untuk dipahami isinya, disampaikan kepada kita dengan cara mutawatir, ditulis dalam mushaf yang dimulai dari surat al-Fatihah dan diakhiri dengan surat al-Nas. ${ }^{20}$.

Al-Qur'ān berfungsi sebagai Huda (petunjuk) dari Allah SWT, yang tidak diragukan lagi kebenarannya ${ }^{21}$. Sebagaimana dijelaskan dalam firmanNya:

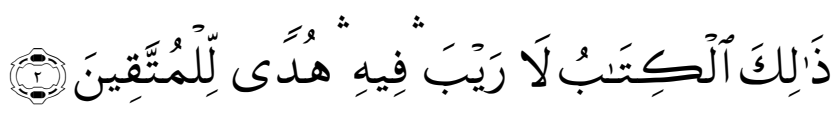

Kitab (Al Quran) ini tidak ada keraguan padanya; petunjuk bagi mereka yang bertaqwa. (QS. Al-Baqarah: 2) ${ }^{22}$.

${ }^{20}$ Azqiara, Pengertian Al-Qur'an Menurut Babasa dan Istilah, www.google.com

${ }^{21}$ Ahmad Annuri, Panduan Tabsin Tilawab Al-Qur'an \& Ilmu Tajwid (Jakarta: Pustaka Al-Kautsar, 2015), h. xxxi.

22 Al-Jumanatul 'Ali, Al-Qur'an dan terjemahnya, (Bandung: CV Penerbit J-ART, 2003), 2 
Dengan demikian maka al-Qur'ān menjadi kitab bagi seluruh manusia dan kitab bagi seluruh kehidupan. Bukan ditujukan untuk satu bangsa tertentu atau kalangan orang tertentu, tapi untuk semua golongan manusia ${ }^{23}$.

Membaca al-Qur'ān merupakan ibadah. Pada hari kiamat kelak akan memberi syafa'at kepada para pembacanya. Rasulullah SAW bersabda:

Bacalah al-Qur'ān, karena sesungguhnya ia akan datang pada hari kiamat sebagai pemberi syafa'at kepada para pembacanya. ${ }^{24}$.

Berdasarkan pengertian, diketahui bahwa maksud dari pembelajaran tahsin tilawah al-Qur'ān adalah sebuah kegiatan yang lebih menekankan pembagusan atau perbaikan dari bacaan al-Qur'ān meliputi tempat keluarnya huruf, sifat huruf dan lain-lain. Hal ini sejalan dengan apa yang disampaikan oleh Ahmad Annuri bahwa yang dimaksud dengan tahsin tilawah adalah upaya untuk memperbaiki dan membaguskan bacaan al-Qur'ān ${ }^{25}$.

\section{B. Pentingya Tahsin Tilawah Al-Qur'ān}

1. Karena Allah mencintai al-Qur'ān sebagaimana ayat-ayat al-Qur'ān itu diturunkan.

2. Mudah dihayati oleh pembaca dan orang yang mendengarkan.

3. Memudahkan seseorang meraih pahala dari Allah dengan tilawah yang bagus.

4. Seseorang dapat mengajarkan kepada orang lain bila sudah mampu membaca dengan baik.

5. Mendahulukan keluarga dalam mengajarkan al-Qur'ān.

6. Dapat mengangkat kualitas seseorang dengan tilawah yang bagus.

23 Zeid B. Smeer, Ulumul Hadits Pengantar Studi Hadits Praktis (Malang: UIN-Malang Press, 2008), 60

${ }^{24}$ Modul Tahsin Al-Qur'an Untuk Mahasiswa Polban, www. Google.com

${ }^{25}$ Ahmad Annuri, Panduan Tabsin Tilawah Al-Qur'an \& Ilmu Tajwid (Jakarta: Pustaka Al-Kautsar, 2015), 3 


\section{Target Tahsin Tilawah Al-Qur'ān}

Diantara target tilawah al-Qur'ān adalah:

1. Dapat mengucapkan huruf hijaiyah dengan benar.

2. Dapat membaca ayat al-Qur'ān sesuai dengan hukum tajwid.

3. Lancar membaca ayat al-Qur'ān sesuai hukum tajwid.

4. Mampu menghafal dan melafalkan huruf-huruf sesuai kaidah tajwid.

5. Menguasai kaidah ilmu tajwid (kecil kemungkinan melakukan kesalahan saat membaca al-Qur'ān).

6. Mampu mengajarkan kepada keluarga dan masyarakat ${ }^{26}$.

Secara umum Abu Qawwam mengatakan bahwa target tahsin tilawah alQur'ān adalah agar benar pengucapan hurufnya, tepat ukuran panjang pendeknya, pas dalam memulai dan berhenti dan memperindahnya dengan menyempurnakan ghunnah serta tebal-tipis ${ }^{27}$.

\section{Tujuan Tahsin Tilawah Al-Qur'ān}

Berdasarkan pembahasan diatas maka tujuan tahsin tilawah adalah menjaga lisan dari kesalahan-kesalahan dalam membaca al-Qur'ān. Kesalahan dalam membaca al-Qur'ān sendiri ada 2 macam yaitu: ${ }^{28}$.

1. Al-Lahnul Jaliy

Al-Lahnul Jaliy adalah kesalahan yang terjadi pada lafazh ketika membaca al-Qur'ān, baik kesalahan itu mengubah makna atau tidak, seperti mengubah salah satu huruf dengan huruf yang lainnya, atau mengubah salah satu harakat dengan harakat lainnya.

${ }^{26}$ Ahmad Annuri, Panduan Tahsin Tilawah Al-Qur'an \& Ilmu Tajwid (Jakarta: Pustaka Al-Kautsar, 2015), 13

${ }^{27}$ Abu Qowwam, http://www.dakwatuna.com/2014/01/29/45466/bukan-tahsin-al-quran-tapi-tahsintilawah

${ }^{28}$ Tahsin Qur'an, Ilmu untuk menyempurnakan belajar al-Qur'an, https:/islamdownload.net/125617 -tahsinqur'an-ilmu-untuk-menyempurnakan-belajar-al-qur'an-html 
2. Al-Lahnul Khofiy

Al-Lahnul khofiy adalah kesalahan ringan ketika membaca al-Qur'ān (tidak mengubah makna/arti) seperti tidak membunyikan dengung, kurang panjang dalam membaca mad wajib dan sebagainya ${ }^{29}$.

Secara umum Zarkasyi mengatakan bahwa tujuan tahsin tilawah adalah agar lisan (mulut) terhindar dari kesalahan dan perubahan saat membaca ${ }^{30}$.

\section{E. Strategi dan Langkah-langkah Pembelajaran Tahsin Tilawah Al-Qur'ān}

Strategi pembelajaran menurut Zarkasyi adalah sebagai berikut:

1. Sistem sorogan atau individu (Privat).

Proses belajar mengajar dilakukan dengan cara satu persatu. Siswa atau santri secara bergiliran membaca menurut kemampuannya.

2. Klasikal-Individu.

Pembelajaran secara massal (bersama-sama) dalam suatu kelompok atau kelas.

3. Klasikal Baca Simak

Mengajar diawali dengan strategi klasikal kemudian dilanjutkan mengajar individu, tetapi disimak oleh guru dan peserta didik lainnya. Dengan demikian apabila ada peserta didik sedang membaca, yang lain menyimak. sehingga jika ada kesalahan dalam membaca, maka teman-teman dan guru bisa langsung menegurnya ${ }^{31}$.

Adapun langkah-langkah pembelajarannya adalah sebagaimana berikut ini:

a) Persiapan

1) Pembukaan dan doa.

2) Menyiapkan jilid atau al-Qur'ān dan alat tulis.

3) Menyediakan buku rekapan nilai untuk melihat perkembangan peserta didik.

${ }^{29}$ Ahmad Annuri, Panduan Tabsin Tilawah Al-Qur'an \& Ilmu Tajwid (Jakarta: Pustaka Al-Kautsar, 2015), 23

${ }^{30}$ K.H. I. Zarkasyi, Pelajaran Tajwid, (Gontor Ponorogo: TRIMURTI PRESS, 1995), vi

31 Zarkasyi, Merintis Pendidikan TKA, (Semarang 1987), 13-14 
b) Kegiatan inti

1) Mengemukakan tujuan pembelajaran

2) Menyampaikan materi yang akan dipelajari

3) Peserta didik mengulang-ulang bacaan agar cepat menguasai.

4) Peserta didik mempraktekan bacaan al-Qur'ān sesuai tajwid yang benar.

5) Guru menyimak lalu menegur jika ada yang keliru dalam membaca. Peserta didik yang lainnya juga harus serius memperhatikannya.

6) Guru memberikan evaluai dan memberi semangat keseluruhan guna memberikan penguatan.

c) Penutup

1) Menyampaikan pokok materi yang akan datang.

2) Menutup dengan mengucap hamdalah/doa ${ }^{32}$.

\section{F. Materi Pokok Tahsin Tilawah Al-Qur'a>n}

1. Makharijul Huruf (Tempat Keluarnya Huruf)

Tempat keluarnya terbagi menjadi lima macam:

\begin{tabular}{|c|c|c|}
\hline \multirow[t]{3}{*}{ Rongga mulut (او ي) } & Membuka mulut dengan sempurna & 1 \\
\hline & Dikedua bibir atas dan bawah & g \\
\hline & Menurunkan bibir bagian bawah & ي \\
\hline \multirow{5}{*}{ 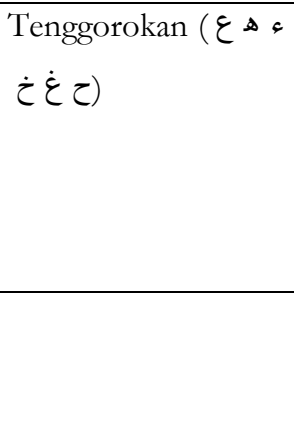 } & Ditenggorokan bagian bawah & 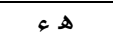 \\
\hline & Tenggorokan tengah & $\varepsilon \tau$ \\
\hline & Tenggorkan atas & $\dot{\varepsilon} \dot{\tau}$ \\
\hline & Pangkal lidah & ك ق \\
\hline & Tengah lidah dengan langit-langit & ي ش ج \\
\hline
\end{tabular}

${ }^{32}$ Agus Dwi Prasojo, Penggunaan Metode Tabsin Terhadap Kemampuan Membaca Al-Quran Pada Mata Pelajaran Al-Quran Hadits Kelas V Di Mima IV Sukabumi, 2018, www.google.com 


\begin{tabular}{|c|c|c|}
\hline \multirow{7}{*}{ 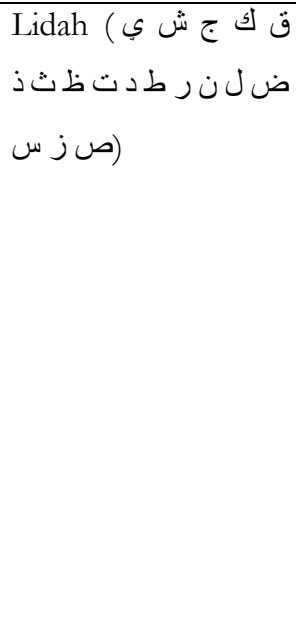 } & Tepi lidah dengan gigi geraham atas & 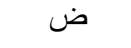 \\
\hline & Lidah depan dengan gusi atas & ض ل ل \\
\hline & Ujung lidah dibawah makhroj lam & ن ل \\
\hline & Ujung lidah & 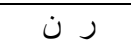 \\
\hline & Ujung lidah dengan pangkal gigi seri & ط د ت \\
\hline & Ujung lidah bertemu ujung gigi seri atas & ص س ز \\
\hline & Ujung lidah dengan ujung dua buah gigi atas & ظ ذ ذ ث \\
\hline \multirow[t]{3}{*}{ Dua Bibir ( و ب مجف) } & $\begin{array}{l}\text { Bagian tengah dari bibir bawah dengan ujung dua gigi } \\
\text { atas }\end{array}$ & ف \\
\hline & Di kedua bibir atas dan bawah bersama-sama & ب ب م \\
\hline & Dua bibir membentuk bulatan & و \\
\hline Rongga Hidung & $\begin{array}{l}\text { Semua bacaan dengung yang keluar dari rongga } \\
\text { hidung }^{33} \text {. }\end{array}$ & \\
\hline
\end{tabular}

\section{Sifat-Sifat Huruf}

Sifat-sifat huruf itu ada 17 macam. Sepuluh macam berlawanan dan tujuh macam tidak berlawanan.

\begin{tabular}{|c|c|c|}
\hline \multirow{6}{*}{$\begin{array}{l}\text { Sifat yang } \\
\text { memiliki } \\
\text { lawan kata }\end{array}$} & Hams/lepas nafas & ف ح ث هـ خ ص س ك ت \\
\hline & Jabr/tahan nafas & ع ظ مو ز ن ق ار ء ذ ي غ ض ج د طل ب \\
\hline & Syiddab/tahan suara & ع جد ق ط ب ك ت \\
\hline & Rakhawah/lepas suara & خ ذ غ ث حظ ف ض ش و صز ي \\
\hline & Isti'la /lidah naik ke langit-langit & خ ص ض غ طق ظ \\
\hline & Istifal/merendahkan lidah & ث ب ت عز من بي جو د حر فه ذ ذس ل \\
\hline
\end{tabular}

${ }^{33}$ K.H. Ahmad Rifa'I Yasin, Panduan Tajwid Praktis, (Jakarta: Afwaaja-Nizhom, 2000), 27 


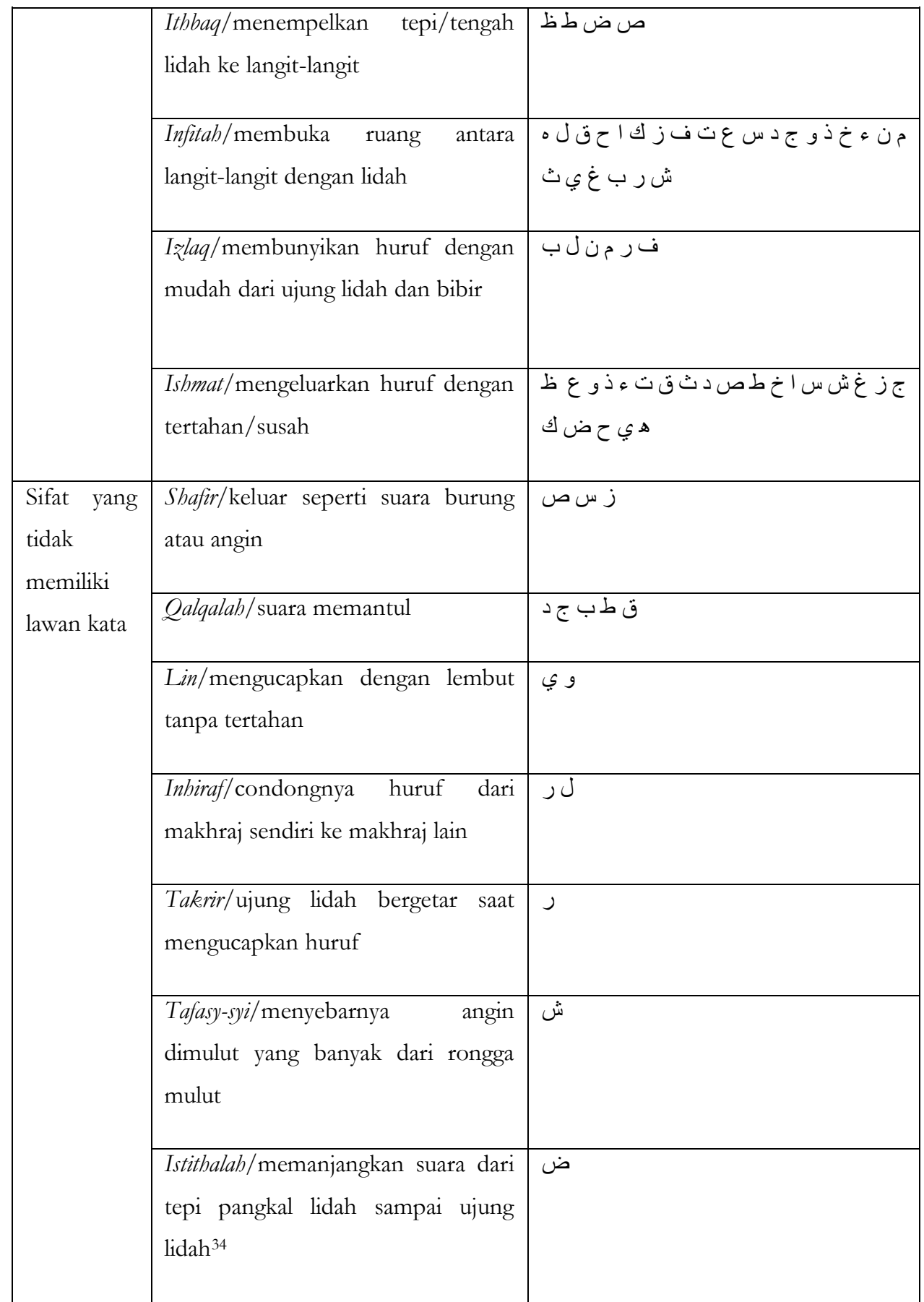

${ }^{34}$ Ahmad Annuri, Panduan Tabsin Tilawah Al-Qur'an \& Ilmu Tajwid (Jakarta: Pustaka Al-Kautsar, 2015), 65 
3. Hukum Nun sukun dan Tanwin

a. Izhar halqi (jelas atau terang tanpa ghunnah/ mendengung ketika bertemu huruf $\dot{\varepsilon} \varepsilon \dot{\tau} \tau \otimes 1)$

Contoh: مِنْ أمَّة

b. Idgam bighunnah (nun mati dan tanwin dimasukkan kedalam 4 huruf

g) dan ditahan selama 2 harakat

Contoh: مَنْ نِنِمَة

c. Idgham bilaghunnah (nun mati dan tanwin dimasukkan kedalam 2 huruf yaitu $J$ dan $\jmath$ ) tanpa ditahan

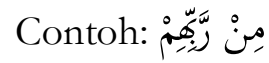

d. Iqlab (suara nun diganti dengan suara mim disertai dengung ketika bertemu huruf $\varphi)$

Contoh: آَنْبَاََهُمْ

e. Ikha' (samar-samar. Artinya saat baca dengung nun mati dan tanwin, lidah sudah siap untuk baca huruf ikhfa'. Huruf-hurufnya yaitu: ت ك

Contoh: يَنْصرُوُْمْ

4. Hukum Mim Sukun

a. Ikhfa' Syafawi (bunyi mim nya dibaca dengung dan agak samar. Bibir jangan terlalu rapat.

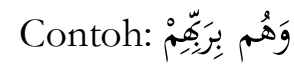

${ }^{35}$ M. Misbachul Munir, Pedoman Lagu-Lagu Tilawatil Qur'an Dilengkapi Dengan Tajwid \& Qosidah, (Surabaya: Apollo, 1997), 153 
b. Idgham Mimi (bunyi mim dibaca dengung)

Contoh: كَمْ مِنْ فِئَة

c. Izhar Syafawi (mim dibaca jelas tanpa dengung ketika mim mati bertemu

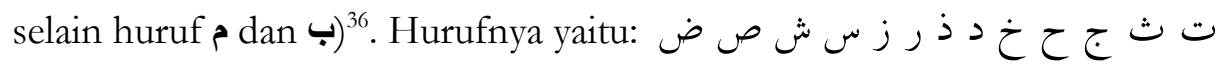

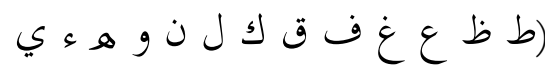

Contoh: المَّ تَعْلَمْ

5. Hukum Mim dan Nun Bertasydid

a. نّ didengungkan dan ditahan 2 harakat.

b. ’̆didengungkan dan ditahan 2 harakat ${ }^{37}$. Contoh:

\begin{tabular}{|c|c|}
\hline 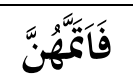 & نّ \\
\hline مِنَ الغَمِّ & $\ddot{\rho}$ \\
\hline
\end{tabular}

6. Macam-macam Idgham

a. Idgham mutamatsilain (adanya huruf yang dibaca sukun bertemu huruf hidup yang sama/bertemunya huruf yang sama makhraj dan sifatnya)

Contoh:

b. Idgham mutajanisain (mengidghamkan huruf ke dalam huruf yang sama makhrajnya namun lain sifatnya)

Contoh:

\begin{tabular}{|c|c|}
\hline ل أئن بسطت & - - \\
\hline أجيتُدعوتكما & $ت$ \\
\hline
\end{tabular}

${ }^{36}$ KH. I. Zarkasyi, Pelajaran Tajwid, (Gontor Ponorogo: TRIMURTI PRESS, 1995), 5

${ }^{37}$ K.H. Ahmad Rifa'I Yasin, Panduan Tajwid Praktis, (Jakarta: Afwaaja-Nizhom, 2000), 24 
c. Idghammutaqaribain (mengidghamkan huruf ke dalam huruf yang berdekatan makhraj dan sifatnya) ${ }^{38}$.

Contoh:

\begin{tabular}{|c|c|}
\hline الَمْ نَخْلَقَكُمْ & ق - ك \\
\hline وقل ربّي & נ J J \\
\hline
\end{tabular}

7. Hukum Mad

a. Mad Ashli/ Mad Thabi'i (panjangnya hanya 2 harakat)

1) Fathah diikuti Alif ('). Contoh: قَال

2) Dhammad diikuti Wau (9) yang bersukun. Contoh: يُقْول

3) Kasrah diikuti Ya' (يْْه : (ي) yang bersukun. Contoh

b. Mad Far'i

1) Karena Hamzah

أؤلئك : Mad wajib muttashil (4, 5, boleh 6 harakat ketika waqaf). Contoh

Mad jaiz munfashil (2, 4, 5 harakat). Contoh: وما أُمِروْا

مالَهُ Mad shilah thawilah (2, 4, 5 harakat). Contoh

Mad badal (2 harakat). Contoh: أُْْتِى

2) Karena Sukun

Mad 'aridh lisskun (2, 4, 6 harakat). Contoh: العلميْن

فلاخوف Mad lin (2, 4, 6 harakat). Contoh:

Mad 'iwadh (2 harakat). Contoh: عليماحكيما

وإذاحيَيْنُمُ Mad tamkin (2 harakat). Contoh

Mad farq (6 harakat). Contoh: قل آلله أذن لكم

Mad shilh qashirah (2 harakat). Contoh: به جميعا

38 M. Misbachul Munir, Pedoman Lagu-Lagu Tilawatil Qur'an Dilengkapi Dengan Tajwid \& Qosidah, (Surabaya: Apollo, 1997), 159 
Mad lazim (mad lazim kilmi mutsaqqal 6 harakat, mad lazim kilmi mukhaffaf 6 harakat, mad lazim harfi mutsaqqal 6 harakat dan mad lazim harfi mukhaffaf 6 harakat) ${ }^{39}$.

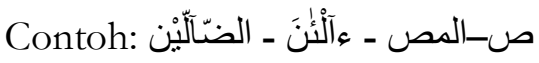

8. Hukum Ro' dan Lamyang dibaca tebal dan tipis

a. Hukum Ro'

1) Dibaca tafkhim/tebal

Ro’ yang berharakat fathah/fathatain (مِدْرَ) ارًا (2)

Ro’ yang berharakat dhammah/dhammatain (سُرْرِ (1)

- مَاََرْنَلَ) Ro' sukun yang didahului oleh huruf berharakat fathah/dhammah (يُرْجَعْوْنَ)

Ro' sukun karena waqaf dan sebelumnya berupa alif atau wawu sukun

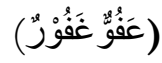

Ro' sukun karena waqaf, sebelumnya berupa huruf mati yang didahului fathah/dhammah (وَالفَجْرْ)

Ro'sukun yang didahului oleh hamzah washal (hamzah yang bila didahului

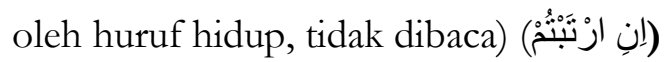

Ro' sukun sebelumnya dibaca kasrah dan diikuti huruf isti'la dalam satu kalimat (فِيْ قِرَْْاسِ)

2) Dibaca tarqiq/tipis

Ro' berharakat kasrah/kasratain (كَ)

Ro’ sukun yang didahului oleh huruf berharakat kasrah (فَزْْ عَوْنَ)

Ro' sukun karena waqaf sebelumnya ada ya' sukun (بَصِيْرِ)

Ro' sukun karena waqaf sebelumnya ada huruf mati yang didahului oleh harakat kasrah (لَِِّي حِجْر)

3) Boleh dibaca tafkhim/tebal dan tarqiq/tipis

Jika waqaf boleh tafkhim/tarqiq, tetapi tafkhim lebih utama (أُدْلوا مصنْر)

Jika waqaf boleh tafkhim/tarqiq, tetapi tarqiq lebih utama (عيْن القِطٍِِ)

${ }^{39}$ Ahmad Annuri, Panduan Tabsin Tilawah Al-Qur'an \& Imu Tajwid (Jakarta: Pustaka Al-Kautsar, 2015), 121 
Jika waqaf boleh tafkhim/tarqiq (فذوقو اعذابي ونذرِ)

b. Hukum Lam

1) Lam yang dicaca tebal (lam jalalah/lam pada lafadz Allah yang didahului harakat fathah atau dhammah seperti: هو الله - رسول الله )

2) Lam yang dibaca tipis (lam jalalah yang didahului harakat kasrah ${ }^{40}$.Contoh: والله الحمد - بسم الله

c. Hukum Lam Ta'rif

1) Izhar Qomariyah (apabila ada lam ta'rif/ ال bertemu/dihubungkan dengan salah satu huruf (عبخجكوخفعقيمه

Contoh: البَصِنْيُ

2) Idgham Syamsiyah (apabila ada lam ta'rif/J bertemu dengan salah satu huruf 14, yakni semua huruf selain huruf qomariyah: ت ث د ذر زس ش ص

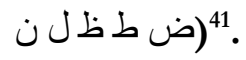

Contoh: النَََّّّبُ

9. Hukum Qalqalah

a. Sughra (memantulkan dengan ringan, apabila huruf qalqalahnya bersukun asli yang terletak ditengah kata. Contoh: ووالعدئت ضبْحا)

b. Kubra (memantulkan dengan berat/jelas apabila huruf qalqalahnya bersukun karena waqaf dan terletak diakhir bacaan. Contoh: قل هو الله احد (قل

10. Tanda Waqaf

Tanda waqaf yang berlaku dalam al-Qur'ān adalah sebagai berikut:

\begin{tabular}{|c|c|c|}
\hline 5 & 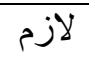 & Berhenti \\
\hline b & مُطْلق & Tempat yang sempurna untuk berhenti \\
\hline 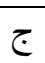 & جائزْ & Boleh berhenti boleh diteruskan \\
\hline j & مُجوَّز & Lebih baik washol \\
\hline
\end{tabular}

${ }^{40}$ M. Misbachul Munir, Op.Cit., 163

${ }^{41}$ KH. I. Zarkasyi, Pelajaran Tajwid, (Gontor Ponorogo: TRIMURTI PRESS, 1995), 8

42 K.H. I. Zarkasyi, Pelajaran Tajwid, (Gontor Ponorogo: TRIMURTI PRESS, 1995), 27 


\begin{tabular}{|c|c|c|}
\hline 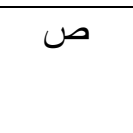 & 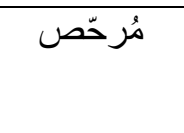 & $\begin{array}{l}\text { Tempat berhenti, sebagai keringanan bagi orang yang } \\
\text { memerlukan }\end{array}$ \\
\hline قف / قلى & الوقْف اولى & Berhenti lebih utama \\
\hline صلى & الوصل اولى & Diteruskan lebih utama \\
\hline ق & قايل عليه & Lebih baik washol \\
\hline$\gamma$ & لاوقف فيه & Tidak boleh berhenti \\
\hline ك5 & كذلك & Sama seperti waqaf sebelumnya \\
\hline$\therefore$ & معانقة & Berhenti pada salah satunya ${ }^{43}$ \\
\hline
\end{tabular}

11. Istilah-Istilah Dalam Membaca al-Qur'ān

a. Sajdah (disunnahkan untuk sujud baik didalam atau diluar shalat. Contoh Q.S 7:206 dan lain-lain)

b. Saktah (berhenti sebentar tanpa bernapas. Contoh: Q.S. 18:1-2 dan lain-lain).

c. Isymam (menampakan dhammah yang terbuang dengan isyarat bibir/menggabungkan dua bibir. Contoh: Q.S. 12:11 dan lain-lain)

d. Imalah (fathah dibaca miring ke kasrah. Contoh: Q.S. 11:41 dan lain-lain).

e. Tashil (hamzah kedua dibaca seperti ( $\$$ ) yang dipelankan. Contoh: Q.S. 41:44 dan lain-lain).

f. Naql (memindahkan harakat hamzah ke huruf sebelumnya. Contoh: Q.S. 46:11 dan lain-lain).

g. Roum (memindahkan huruf sebagian harakat. Contoh: Q.S. 1:5 dan lain-lain).

h. Nun wiqoyah (bila ada tanwin dhammah atau kasrah bertemu hamzah washal, maka jika diwashalkan tanwin diganti dengan nun kecil (nun 'iwadh) yang dibaca kasrah. Contoh: Q.S. 2:61 dan lain-lain) ${ }^{44}$.

${ }^{43}$ K.H. Ahmad Rifa’i Yasin, Panduan Tajwid Praktis, (Jakarta: Afwaaja-Nizhom, 2000), .54

${ }^{44}$ Ahmad Annuri, Panduan Tabsin Tilawab Al-Qur'an \& Ilmu Tajwid (Jakarta: Pustaka Al-Kautsar, 2015), 199 


\section{KESIMPULAN}

Tahsin berasal dari kata Hasana, Yabsunu, Tahsinan yang artinya memperbaiki, membaguskan, menghiasi, mempercantik, membuat lebih baik dari semula. Adapun Tilawah artinya bacaan. Sedangkan secara istilah ialah membaca al-Qur'ān dengan bacaan yang menjelaskan huruf-hurufnya dan berhati-hati dalam melaksanakan bacaannya, serta melafalkan dengan nada yang indah. Al-Qur'ān dari segi bahasa artinya "bacaan" atau "sesuatu yang dibaca berulang-ulang". sedangkan secara istilah berarti kitab suci umat Islam yang di dalamnya berisi firman Allah SWT yang diturunkan kepada Rasulullah SAW sebagai mukjizat. Dengan demikian maka dapat disimpulkan bahwa tahsin tilawah al-Qur'ān merupakan sebuah upaya untuk mempelajari dan memperbaiki bacaan al-Qur'ān meliputi tempat keluar huruf, sifat huruf, hubungan antara huruf, hukum mad (panjang dan pendeknya dalam melafazkan ayat al-Qur'ān) dan waqaf (mulai baca dan berhenti pada bacaan) serta istilah-istilah dalam al-Qur'ān dan lain sebagainya yang berkaitan dengan pembelajaran al-Qur'ān. Melalui pembelajaran tahsin tilawah ini diharapkan dapat meningkatkan kualitas bacaan terutama bagi bagi mereka yang termasuk dalam kategori pembaca pemula.

\section{DAFTAR PUSTAKA}

Ahmad Annuri, Panduan Tabsin Tilawah Al-Qur'an \& Ilmu Tajwid, Jakarta: Pustaka AlKautsar, 2015

Al-Jumanatul 'Ali, Al-Qur'an dan Terjemahnya, Bandung: Penerbit J-ART, 2003

K.H. Ahmad Rifa'I Yasin, Panduan Tajwid Praktis, Jakarta: Afwaaja-Nizhom, 2000

KH. I. Zarkasyi, Pelajaran Tajwid, Gontor Ponorogo: Trimurti Press, 1995

M. Misbachul Munir, Pedoman Lagu-Lagu Tilawatil Qur'an Dilengkapi dengan Tajwid \& Qosidah, Surabaya: Apollo, 1997

M. Quraish Shihab, Wawasan Al-Qur'an Tafsir Maudhu'i Atas Berbagai Persoalan Umat, Bandung: Mizan, 2007

Muhammad Ishak Syafaruddin Masganti Sit, Pelaksanaan Program Tilawah Al-Qur'an dalam Meningkatkan Kemampuan Membaca Al-Qur'an Siswa di Mas AlMa'sum Stabat", Pascasarjana UIN Sumatera Utara, 2017 
Zarkasyi, Merintis Pendidikan TKA, Semarang 1987

Zeid B. Smeer, Ulumul Hadits Pengantar Studi Hadits Praktis, Malang: UIN-Malang Press, 2008

Abu Qowwam, http://www.dakwatuna.com/2014/01/29/45466/bukan-tahsin-alquran-tapi-tahsin-tilawah

Agus Dwi Prasojo, Penggunaan Metode Tahsin Terhadap Kemampuan Membaca Al-Quran Pada Mata Pelajaran Al-Quran Hadits Kelas V Di Mima IV Sukabumi, 2018, www.google.com

Ahmad Hasim Fauzan, Pola Pembinaan Baca Tulis Al-Qur'an (BTQ) Sebagai Upaya Peningkatan Kemampuan Membaca Al-Qur'an, www.google.com

Azqiara, Pengertian Al-Qur'an Menurut Bahasa dan Istilah, www.google.com

Lynda Fitri Ariyanti, Skripsi:Implementasi Metode Tahsin Dalam Pembelajaran Membaca AlQur'andi Smp Negeri 4 Ungaran Kabupaten Semarang Tabun Ajaran 2016/2017, Salatiga, 2016

Modul Tahsin Al-Qur'an Untuk Mahasiswa Polban, www. Google.com

Tahsin Qur'an, Ilmu untuk menyempurnakan belajar al-Qur'an, https:/islamdownload.net/125617-tahsin-qur'an-ilmu-untukmenyempurnakan-belajar-al-qur'an-html

Tamrin, Pola Pembinaan Tabsin Dikalangan Mahasiswa, www. Google.com

Wikipedia Bahasa Indonesia, Tahsin, id.m.wikipedia.org/wiki/tahsin 